\title{
A Mixed Model Analysis of a Fertilizer Experiment on Oil Palm in Nigeria
}

\author{
Edwin A. Iguodala1, Eghwerido Joseph Thomas2*, Austin Edokpayi1, Obilade Titilola ${ }^{3}$ \\ ${ }^{1}$ Nigerian Institute for Oil Palm Research, Benin City, Nigeria \\ ${ }^{2}$ Department of Mathematics and Computer Science, Federal University of Petroleum Resources, \\ Effurun, Nigeria \\ ${ }^{3}$ Department of Mathematics, Obafemi Awolowo University, Ile-Ife, Nigeria \\ Email: eddyrandley2k@yahoo.com, “eghwerido.joseph@fupre.edu.ng, edokpayiaustine@yahoo.com, \\ tobilade@yahoo.com
}

Received 26 May 2016; accepted 12 August 2016; published 16 August 2016

Copyright (C) 2016 by authors and Scientific Research Publishing Inc.

This work is licensed under the Creative Commons Attribution International License (CC BY). http://creativecommons.org/licenses/by/4.0/

(c) ()) Open Access

\begin{abstract}
Mixed model analysis procedure was used to analyze the effect of fertilizer application on the Fresh Fruit Bunch (FFB) yield of oil palm. This was with a view to achieve the most appropriate and a robust model for analyzing yield response for fertilizer application in oil palm. In this study, a mixed model analysis procedure was used to analyze yield data obtained from a fertilizer trial conducted between 1997 and 2005. In mixed effect model, replicates and years were used as block. In contrast the fixed effect ANOVA model usually lumped up replicates and years as a random error. In the model replicates were used as block with no block interaction, replicates as block with allowance for block-fertilizer interaction, years as block with allowance for block-fertilizer interaction, and years and replicates as block with allowance for year fertilizer and replicate-fertilizer interaction. Mixed model theory was also used to provide the explicit description of the design matrices in the models. Also, hypotheses relevant to each model were formulated and used to test for specific effects in the models such as, fixed part, random part and interacting parts using appropriate error terms as determined by the derived Expected Mean Squares (EMS). The results revealed that at $5 \%$ significant level $(p<0.05)$, the combination of Potassium $(K)$ at $3.5 \mathrm{~kg}$ and magnesium (Mg) at $1.7 \mathrm{~kg}$ was sufficient for bunch yield of oil palm as the effect of fertilizer application was significant in the interactions of $K$ and Mg due to treatment.
\end{abstract}

\section{Keywords}

Fixed Model, Random Model, Mixed Model, Oil Palm, Fertilizer Trial

\footnotetext{
${ }^{*}$ Corresponding author.
} 


\section{Introduction}

Oil palm fertilizer trials are often large, complex, expensive and need time to accomplish. Usually, fixed effect ANOVA is a common tool in resolving yield responses in fertilizers in the oil palm. Thus, properly designed and analyzed experiments provide the maximum amount of information about the conditions investigated for the resources used. Experimental design is concerned with planning experiments in order to obtain the maximum amount of information from the available resources. Often the experimenter has control over certain treatments effect and populations, or treatments combinations. The experimenter generally controls the choice of the experimental units and whether those experimental units need to be put into groups or blocks, depending on what are to be compared or whose effects are to be studied. Hence, we seek to enhance strategies of applying mixed model analysis procedure for fertilizer experimentation on oil palm. The insights reveal the advantage of using mixed model analysis for potassium (K) and magnesium (Mg) fertilizer trials. In that the model identifies certain effects that are hidden in Analysis of Variance (ANOVA).

The model for data from a randomized blocks design should usually contain fixed effects for treatment contributions and random effects for block contributions, making it a mixed model. Hence with the mixed procedure the problems arising from balanced and unbalanced data, correlated data, missing plots, unequal numbers of samples and unequal variances associated with the use of Analysis of variance (Fixed effect) techniques will be resolved. This work attempts to employ mixed model to a fertilizer experiment conducted by NIFOR scientist in the influence of potassium and magnesium fertilizer on fresh fruit bunch yield of oil palm.

Airy [1] gave the first known formulation of a variance components model while considering a standard measurement problem in astronomy. Benjamin and Amy [2] proposed a simple approach for testing random effects in the linear mixed model using Bayes factors. Brien and Bailey [3] described the method for formulating a mixed model for an experiment without describing explicitly how data with longitudinal observations might be handled. Chi and Reinsel [4] considered the linear mixed model when the variance-covariance matrix of the random errors had the structure of an autoregressive process of order 1. Chiarandini and Goegebeur [5] reviewed linear statistical models for the analysis of computational experiments. These models separated the effects of algorithmic components and instance features included in the analysis. Crump [6] considered maximum likelihood estimation for normal distribution variance components models, whose optimization was usually done through the use of the Expectation-Maximization (EM) algorithm, Dempster et al. [7] and Newton-Raphson methods (Thisted [8]), but the latter was seen to be more efficient than the former (Lindstrom and Bates [9]). Duchateau et al. [10] applied mixed model analysis in veterinary research by fixing data structure in mixed models notation by comparing doses of drug at different experimental design units such as completely randomized design, randomized block design and split-plot design, where they specified the complex data structures in a natural way in the mixed model framework. Fisher [11] [12] introduced ANOVA method to estimate the variance components through the use of expected mean squares. Foster [13] [14] emphasized on the fertilizer requirements of oil palm which depended on many interrelated factors that varied from one environment to another. Gelfand et al [15] presented a Bayesian analysis of the generalized linear mixed model using the Gibbs sampler. Gelman [16] stated that a regression model, possibly with multiple error terms and conversely ANOVA tools, can be used to summarize an existing linear model. Hartley and Rao [17] made landmark contributions to the theory of maximum likelihood estimation for variance components, and established the first asymptotic results for MLE. Harville [18] [19] presented a comprehensive review of maximum likelihood estimation in linear mixed effects models, and introduced the general linear mixed model structure in matrix notation. Henderson [20]-[23] worked extensively on ANOVA estimation for unbalanced data, and evolved three ANOVA methods that were later known as Henderson methods. Maximum likelihood estimation in linear mixed models for repeated measures with structured variance-covariance matrices was considered by Jenrich and Schluchter [24], and this was extended to the general linear mixed effects models by Wolfinger et al. (1991), with some attention given also to the restricted maximum likelihood method. Laird and Ware [25] presented a general linear mixed effects model for repeated measures data and suggested the use of the EM algorithm for obtaining restricted maximum likelihood estimators of the variance-covariance components. Liang and Zeger [26] described the generalized linear model with allowance for a more flexible error structure that was not restricted to be normally distributed, and further introduced the idea of a link function. This model is a competitor of the nonlinear mixed effects model. Makinde et al. [27] conducted a field experiment to investigate the effects of organic, organomineral and NPK fertilizer on the yield of Amaranthus cruentus L. using a randomized complete block design in 
four replications and the data was analyzed using ANOVA. Melaniel and Gary [28] applied mixed model for the analysis of replicated spatial point patterns by carrying out a simulation experiment on parameter estimation where the fixed effect and mixed effect models were compared. Miller [29] went further in establishing and giving conditions under which asymptotic results held for a large class of variance components models. The asymptotic distribution of the estimates of Maximum Likelihood for mixed effects ANOVA models was derived, by Miller following the work by Hartley and Rao [17], but the results had not been extended to more general linear mixed effects models. ONeill stated that the likelihood of such random sample of size $\mathrm{n}$ is simply the product of the density function of the Normal distribution evaluated at each of the data point. Patterson and Thompson [30] developed the restricted maximum likelihood (REML) method for unbiased estimates of variance components through the use of maximum likelihood principle. Piepho et al. [31] [32] derived the mixed models for experiments which involve longitudinal observations. Smith et al. [33] provided an overview for current mixed model approaches in the analysis of crop cultivar breeding and evaluation trials. Tippet [8] further clarified the use of the ANOVA method for analysis of variance designs and extended it to 2-way crossed classification mixed effects models. The normal distribution of the random effects was replaced by a multivariate t-distribution by Wakefield et al [34]. Witkovský [35] developed a flexible MATLAB algorithm mixed model to estimate the parameters of the linear mixed model. Yeboah et al. [36] evaluated the effect of organic and inorganic fertilizer on the growth and yield of Artemisia annual. The experiment was arranged in a randomized complete block design with three replications and six treatments. The data were statistical analysis using Genstat at 5\%. Zhu Jun [37] used mixed models approaches to estimate genetic covariance between two traits with unequal design matrices. He developed an application to demonstrate how to estimate covariance components between seed traits and maternal plant traits. Minimum Norm Quadratic Estimators (MINQUE) (0/1) method, which was a MINQUE method setting 0 for prior covariance between direct and maternal effects and 1 for other prior covariance, was shown to be suitable for estimating covariance components without using iteration.

\section{Material and Method}

\subsection{Geographical Features of the Study Area}

This study was conducted at the Okomu Oil Palm Plantation at Udo near Benin City, Nigeria (05037'E, 06033' $\mathrm{N}$ and $149 \mathrm{~m}$ above sea level). Benin City lies in the rainforest zone of Nigeria and is characterized by high annual rainfall (mean $1800 \mathrm{~mm}$ p.a.) from March to October, with mean maximum temperature of 330C and mean minimum temperature of 210C. However, Okomu altitude is lower than Benin City which is $90 \mathrm{~m}$ above sea level. The natural vegetation of this area is the low land type tropical rain-forest, which composed of a variety of hard wood timbers. The rainforest vegetation in Edo State is among the vegetation that represents the climax vegetation of the Nigerian forest. In the Northern part of the State, the vegetation consists of woody savannah featuring tree species like Parkia biglobosa. The soil in the study area is sandy. The soils derived from the basement complex rocks are mostly well drained with fine textures which are of high agricultural values for the production of both tree and arable crops.

\subsection{Data Colections}

The data were collected from a commercial plantation, the Okomu Oil Palm Plc, Udo, Nigeria. A $5 \times 4$ factorial experiment arranged in a randomized complete block design in four (4) replications was laid out. The field was planted with tenera hybrid obtained from NIFOR, on plot fully guarded with eight (8) palms. Potassium (K) was applied at five levels as muriate of potash (MOP) (0, 1.5, 2.5, 3.5 and $4.5 \mathrm{~kg}$ per palm) while Magnesium (Mg) was applied at four levels as ground dolomite $(0,0.8,1.7$ and $2.6 \mathrm{~kg}$ per palm). The total numbers and weights of bunches, harvested in each year were recorded and the total bunch weight for each was recorded respectively. Four blocking design models were developed to account for possible sources of variability in this experiment according to potassium at $0,1.5,2.5,3.5,4.5 \mathrm{~kg}$ as the level vary from $1,2,3,4,5$ and also for magnesium 0 , $0.8,1.7,2.6 \mathrm{~kg}$ as level 1, 2, 3, 4 .

\subsection{Soil Test}

The soil of the trial site was analyzed prior to commencement of the study as showed in Table 1. Pre-trial ferti- 
lization history of the field was obtained from the estate. Prior to commencement of the experiment, the field had received fertilizer treatments as follows:

- 1994: $0.14 \mathrm{~kg}$ urea, $0.07 \mathrm{~kg}$ single super phosphate and $0.07 \mathrm{~kg}$ muriate of potash per palm,

- 1995: $1.2 \mathrm{~kg}$ per palm of muriate of potash and $0.05 \mathrm{~kg}$ dolomite per palm,

- 1996: $1.0 \mathrm{~kg}$ muriate of potash per palm only in April.

Therefore at the commencement of the tial in 1997, the treatment of 1.5, 2.5, 3.5 and $4.5 \mathrm{~kg}$ per palm of muriate received $1 \mathrm{~kg}$ less than the required dose. In subsequent years the full doses intended were applied.

Lead and soil sample were obtained prior to the first treatment applications in 1997. Soils were obtained from the base of palms in each treatment to a depth of $30 \mathrm{~cm}$. Leaf samples were obtained. Soil and leaf samples were obtained in a similar manner in subsequent years just prior to fertilizer treatment application. Samples were analyzed in the Chemistry Division of the Institute. Records of fresh fruits bunch numbers and bunch weights were obtained from the treatment palm at bunch harvest, usually every fortnight.

Table 2 shows the physical and chemical properties of a typical soil profile of the trial site at Okomu.

\subsection{Model Formulation}

Different models were developed according to their blocking and interaction in characteristics. They are as follows:

Model A: Replicates as Block with no Block Interaction.

$$
Y_{i j k}=\mu \cdots+\alpha_{i}+\beta_{j}+r_{k}+(\alpha \beta)_{i j}+i j k
$$

for, $i=1,2,3,4,5 ; j=1,2,3,4 ; k=1,2,3,4$;

where:

$Y_{i j k}=$ Bunch weight for palm fruits for plant replication $k$ with potassium at level $i$ and magnesium at level $j$.

$\mu \cdots=$ Overall mean.

$\alpha_{i}=$ Specific fixed effect of potassium at level $i$.

$\beta_{j}=$ Specific fixed effect of the magnesium at level $j$.

Table 1. Soil chemical analysis of field, okomu oil palm Co. Plc before first fertilizer treatment.

\begin{tabular}{cc}
\hline $\mathrm{pH}\left(\mathrm{H}_{2} \mathrm{O}\right)$ & 4.100 \\
$\mathrm{~N}(\%)$ & 0.096 \\
Available $\mathrm{P}\left(\mathrm{Mg} \cdot \mathrm{kg}^{-1}\right)$ & 5.500 \\
$\mathrm{pH}\left(\mathrm{H}_{2} \mathrm{O}\right) 1: 1$ & 5.800 \\
Exch. $\mathrm{K} \cdot \mathrm{c} \cdot \mathrm{mol} \cdot \mathrm{kg}^{-1}$ & 0.030 \\
Exch. $\mathrm{Mg} \cdot \mathrm{c} \cdot \mathrm{mol} \cdot \mathrm{kg}^{-1}$ & 0.380 \\
Exch. $\mathrm{Ca} \cdot \mathrm{c} \cdot \mathrm{mol} \cdot \mathrm{kg}^{-1}$ & 1.420 \\
Exch. $\mathrm{Na} \cdot \mathrm{c} \cdot \mathrm{mol} \cdot \mathrm{kg}^{-1}$ & 0.360 \\
\hline
\end{tabular}

Table 2. Physical and chemical properties of a typical soil profile

\begin{tabular}{|c|c|c|c|c|c|c|c|c|c|c|c|c|}
\hline Depth (cm) & Clay & Silt & Sand & $\mathrm{pH}\left(\mathrm{H}_{2} \mathrm{O}\right)$ & $\mathrm{N}$ & Orgc & K & $\mathrm{Ca}$ & $\mathrm{Mg}$ & $\mathrm{H}^{-}$ & $\mathrm{Al}^{+}$ & ECEC \\
\hline & & & & $\%$ & & & & & & \multicolumn{3}{|c|}{$\mathrm{c} \cdot \mathrm{mol} \cdot \mathrm{kg}^{-1}$} \\
\hline $0-13$ & 17.1 & 2.70 & 80.20 & 5.30 & 0.12 & 2.43 & 0.10 & 2.00 & 1.44 & 0.60 & 1.70 & 6.09 \\
\hline $13-45$ & 24.1 & 2.70 & 73.20 & 5.50 & 0.08 & 0.73 & 0.07 & 1.60 & 0.72 & 1.40 & 1.90 & 5.93 \\
\hline $45-72$ & 25.6 & 2.20 & 72.20 & 5.50 & 0.06 & 0.67 & 0.05 & 1.52 & 0.40 & 0.30 & 1.70 & 4.19 \\
\hline $72-110$ & 27.6 & 2.20 & 70.20 & 5.60 & 0.04 & 0.48 & 0.04 & 1.50 & 0.24 & 1.10 & 1.50 & 4.57 \\
\hline $110-142$ & 28.6 & 2.70 & 68.70 & 5.60 & 0.02 & 0.22 & 0.04 & 1.36 & 0.16 & 0.30 & 1.80 & 3.84 \\
\hline
\end{tabular}


$r_{k}=$ Specific random effect of kth block replicate.

$(\alpha \beta)_{i j}=$ Interaction effect between potassium at level $i$ and magnesium at level $j$.

$i j k=$ Random error of plant in replication $k$ to which fertilizer at levels $i$ of potassium and $j$ of magnesium has been applied,

$\mu \cdots+\alpha_{i}+\beta_{j}+(\alpha \beta)_{i j}$ is the fixed effects part of the model and

$r_{k}+i j k$ is the random effects part of the model.

The error term ijk are independent normal random variables with mean zero and variance.

Model B: Replicates as Block with Allowance for Block-Fertilizer Interaction.

$$
Y_{i j k}=\mu \cdots+\alpha_{i}+\beta_{j}+r_{k}+(\alpha \beta)_{i j}+(\alpha r)_{i k}+(\beta r)_{j k}+i j k
$$

for, $i=1,2,3,4,5 ; j=1,2,3,4 ; k=1,2,3,4$;

where:

$Y_{i j k}=$ Bunch weight for palm fruits for plant in replication at level $k$ with potassium at level $i$ and magnesium at level $j$.

$\mu \cdots=$ Overall mean.

$\alpha_{i}=$ Specific fixed effect of the potassium at level $i$.

$\beta_{j}=$ Specific fixed effect of the magnesium at level $j$.

$r_{k}=$ Specific effect of the kth blocked replicate.

$(\alpha \beta)_{i j}=$ Interaction effect between potassium at level $i$ and magnesium at level $j$.

$(\beta r)_{j k}=$ Interaction effect between blocked replication $k$ and magnesium at level $j$.

$(\alpha r)_{j k}=$ Interaction effect between block at replication $k$ and potassium at level $i$.

$i j k=$ Random error of plant in replication $k$ to which fertilizer at level $i$ of potassium and $j$ of magnesium has been applied.

$\mu \cdots+\alpha_{i}+\beta_{j}+(\alpha \beta)_{i j}$ is the fixed effects part of the model and

$r_{i}+(\alpha r)_{k i}+(\beta r)_{k j}+i j k$ is the random effects part of the model. The error term ijk are independent normal random variables with mean zero and variance $\sigma^{2}$

Model C: Years as Block with Allowance for Block-Fertilizer Interaction.

$$
Y_{i j k l}=\mu \cdots+\alpha_{i}+\beta_{j}+r_{k}+t_{l}+(\alpha \beta)_{i j}+(\alpha t)_{i l}+(\beta t)_{j l}+(\alpha \beta t)_{i j l}+i j k l
$$

for, $i=1,2,3,4,5 ; j=1,2,3,4, ; k=1,2,3,4 ; l=1,2,3,4,5$.

where:

$Y_{i j k l}=$ Bunch weight for palm fruits for plant in year $l$ with potassium at level $i$ and magnesium at level $j$, replicates at level $k$.

$\mu \cdots=$ Overall mean.

$\alpha_{i}=$ Specific fixed effect of the potassium at level $i$.

$\beta_{j}=$ Specific fixed effect of the magnesium at level $j$.

$r_{k}=$ specific effect of replicate at level $k$.

$t_{l}=$ specific random effect of time of year $l$.

$(\alpha t)_{i l}=$ Interaction effect between block at year $l$ and potassium at level $i$.

$(\beta t)_{j l}=$ Interaction effect between block at year $l$ and magnesium at level $j$.

$(\alpha \beta)_{i j}=$ Interaction effect between potassium at level $j$ and magnesium at level $j$.

$(\alpha \beta t)_{i j l}=$ Interaction effect between block, potassium and magnesium at levels $i, j$ and $l$ respectively.

$i j k l=$ Random error of plant in year $l$ in replication $k$ to which fertilizer level $i$ of potassium and $j$ of magnesium has been applied.

$\mu \cdots+\alpha_{j}+\beta_{j}+r_{k}+(\alpha \beta)_{i j}$ is the fixed effects part of the model and $t_{l}+(\alpha t)_{i l}+(\beta t)_{j l}+(\alpha \beta t)_{i j l}+i j k l$ is the random effects of the model,

$\beta_{i}, \alpha_{j}$, and $r_{k}$ are constants subject to the restriction: $\beta_{j}=\alpha_{i}=r_{k}=0$

$(\alpha \beta)_{i j}$, $(\alpha r)_{i k},(\beta \alpha r)_{i j k}$ are constant subject to the restrictions that the sums over any subscript are zero. ijkl are independent $N\left(0, \sigma^{2}\right)$.

Model D: Years and Replicates as Block with Allowance for Year-Fertilizer and Replicate-Fertilizer Interaction.

$$
Y_{i j k l}=\mu \cdots+\alpha_{i}+\beta_{j}+r_{k}+t_{l}+(\alpha \beta)_{i j}+(\alpha t)_{i l}+(\beta t)_{j l}+(\alpha r)_{i k}+(\beta r)_{j k}+(\alpha \beta r)_{i j k}+(\alpha \beta t)_{i j l}+i j k l
$$


for, $i=1,2,3,4,5 ; j=1,2,3,4, ; k=1,2,3,4 ; l=1,2,3,4,5$.

where:

$Y_{i j k l}=$ Bunch weight for palm fruits for plant in year $l$ with potassium at level $i$ and magnesium at level $j$ replicated at level $k$.

$\mu \cdots=$ Overall mean.

$\alpha_{i}=$ Specific fixed effect of the potassium at level $i$.

$\beta_{i}=$ Specific fixed effect of the magnesium at level $j$.

$r_{k}=$ specific of replicate at level $k$.

$t_{l}=$ specific random effect of year $l$.

$(\alpha t)_{i l}=$ Interaction effect between block at year $l$ and potassium at level $i$.

$(\beta t)_{j l}=$ Interaction effect between block at year $l$ and magnesium at level $j$.

$(\alpha \beta)_{i j}=$ Interaction effect between potassium at level $i$ and magnesium at level $j$.

$(\alpha \beta r)_{i j l}=$ Interaction effect between block replicate, potassium and magnesium at levels $i, j$ and $l$ respectively.

$(\alpha \beta t)_{i j k}=$ Interaction effect between block year, potassium and magnesium at levels $l, i$ and $j$ respectively.

$i j k l=$ Random error of plant $l$ in replication $k$ to which fertilizer levels $i$ of potassium and $j$ of magnesium has been applied.

$\mu \cdots+\alpha_{i}+\beta_{j}+(\alpha \beta)_{i j}$ is the fixed effects part of the model and

$r_{k}+t_{l}+(\alpha t)_{i l}+(\beta t)_{j l}+(\alpha r)_{i k}+(\beta r)_{j k}+(\alpha \beta r)_{i j k}+(\alpha \beta t)_{i j l}+i j k l$ is the random effects part of the model.

$\beta_{j}, \alpha_{i}$, and $\tau_{k}$ are constants subject to the restriction.

$\beta_{i}=\alpha_{j}=\tau_{k}=0$.

$(\beta \alpha)_{i j},(\alpha \tau)_{j k},(\beta \alpha \tau)_{i j k}$ are constant subject to the restrictions that the sums over any subscript are zero. ijkl are independent $N\left(0, \sigma^{2}\right)$.

\subsection{Matrix Notation}

The above models A, B, C, and D can be presented in a mixed model for randomized complete block design, written in matrix notation (Henderson et al., 1990).

$$
Y=X \beta+Z u+e
$$

where:

$Y$ is a n-vector of observations with mean $E(Y)=X \beta, X$ is an $n \times p$, the known design matrix for the fixed effects,

$\beta$ is the $\mathrm{p}$-vector of parameters for fixed effects,

$u$ is a q-vector of i.i.d random effects with mean $E(u)=0$ and variance-covariance matrix $\operatorname{var}(u)=G$,

$Z$ is an $n \times q$ known matrix for the random effects,

$e$ is an n-vector of i.i.d random error terms with mean $E(e)=0$ and variance $\operatorname{var}(e)=R$.

where: $G$ and $R$ are positive definite matrices.

\subsection{Typical Hypothesis Testing}

H0: There is no significant effect of potassium at different levels of fertilizer potassium application.

H1: There is significant effect of potassium at different levels of fertilizer potassium application.

This test is based on the linearly independent pairwise comparisons among the estimated marginal/observed means.

\section{Result and Discussion}

The analysis of model A showed that for all 5 years procedure in Table 3 were significant in the block-replication at the p-value of the $\mathrm{F}$ test (significant at $5 \%$ level i.e $(\mathrm{p}<0.05)$. While the analysis further shows that there is no significant difference in the level of $\mathrm{K}, \mathrm{Mg}$ and their interaction of the p-value of the $F$ test (significant at $5 \%$ level, i.e $(\mathrm{p}<0.05)$.

The analysis of model B was significant in Table 4, the block-replicates at the p-value of the $\mathrm{F}$ test of $5 \%$ level of significant i.e. $(\mathrm{p}<0.05)$. But the last three years for the mixed procedure show that $(\mathrm{p}<0.05)$ results in no significance in the effect of block-replicate on the bunch weight of oil palm. The analysis further shows that there was no significant difference in the level of $\mathrm{K}, \mathrm{Mg}, \mathrm{K} * \mathrm{Mg}$, Rep * K and Rep * Mg at (p < 0.05). Howev- 
er, the interaction Rep * $\mathrm{K} *$ mg show that there was significant different in the last 3 years of experimentation.

The analysis of model $\mathrm{C}$ in Table 5 showed that procedure were significant for $(\mathrm{p}<0.05)$ in the years effects for the first five years of the experimentation. However, for all the five years of the analysis, the years were not significant $(\mathrm{p}<0.05)$ for both the ANOVA and MIXED model.

Further analysis revealed that there was no significant difference in the main effects and the interactions between all treatments for both the all fixed ANOVA model and Mixed model. The last three years also shows that the interaction of years, $\mathrm{K}$ and $\mathrm{Mg}$ were significant in difference on bunch weight of oil palm. Finally, the interaction of $\mathrm{K}$ and $\mathrm{Mg}$ show a significant difference in the first two years. This means that the interaction has effects on the bunch weight.

Table 3. Mixed model analysis for RCBD on influence of K and Mg for model A all 5 years.

\begin{tabular}{cccccc}
\hline Source of Variation & SS & DF & MS & $F^{*}$ & P-Value \\
\hline Blocks(rep) & $3,615,760,339$ & 3 & $1,205,253,446$ & 34.045 & $0.000^{*}$ \\
K & $57,837,735.8$ & 4 & $14,459,433.96$ & 0.0408 & 0.803 \\
Mg & $12,010,924.6$ & 3 & $4,003,641.539$ & 0.113 & 0.952 \\
K * Mg & $298,259,830$ & 12 & $24,854,985.85$ & 0.702 & 0.750 \\
Error & $1.335 \mathrm{E}+010$ & 377 & $35,402,256.26$ & & \\
Total & $1.061 \mathrm{E}+011$ & 399 & & & \\
\hline
\end{tabular}

Table 4. Mixed model analysis for RCBD on influence of K and Mg for model B All 5 years.

\begin{tabular}{cccccc}
\hline Source of Variation & SS & DF & MS & F* & P-Value \\
\hline Blocks (Rep) & $3,615,760,339$ & 3 & $1,205,253,446$ & 76.348 & 0.033 \\
K & $57,837,735.8$ & 4 & $14,459,433.96$ & 0.425 & 0.788 \\
Mg & $12,010,924.6$ & 3 & $4,003,641.539$ & 0.224 & 0.878 \\
K * Mg & $298,259,830$ & 12 & $24,854,985.83$ & 0.687 & 0.752 \\
Rep * K & $408,428,414$ & 12 & $34,035,701.15$ & 0.941 & 0.519 \\
Rep * Mg & $161,181,169$ & 9 & $17,909,018.83$ & 0.495 & 0.868 \\
Rep * K* Mg & $1,301,704,178$ & 36 & $36,158,449.39$ & 1.008 & 0.460 \\
Error & $1.148 \mathrm{E}+010$ & 320 & $35,860,427.65$ & & \\
Total & $1.061 \mathrm{E}+011$ & 399 & & & \\
\hline
\end{tabular}

Table 5. Mixed model analysis for RCBD on influence of $\mathrm{K}$ and $\mathrm{Mg}$ for model C All 5 years.

\begin{tabular}{|c|c|c|c|c|c|}
\hline Source of Variation & SS & DF & MS & $\mathrm{F}^{*}$ & P-Value \\
\hline Blocks (Year) & 1,931,053,391 & 4 & $482,763,347.9$ & 41.874 & $0.005^{*}$ \\
\hline K & $57,837,735.8$ & 4 & $14,459,433.96$ & 0.910 & 0.482 \\
\hline $\mathrm{Mg}$ & $12,010,924.6$ & 3 & 4,003,641.539 & 0.270 & 0.846 \\
\hline $\mathrm{K} * \mathrm{Mg}$ & $298,259,830$ & 12 & $24,854,985.83$ & 1.296 & 0.252 \\
\hline Year * K & $254,341,158$ & 16 & $15,896,322.34$ & 0.829 & 0.648 \\
\hline Year * Mg & $177,717,796$ & 12 & $14,809,816.34$ & 0.772 & 0.675 \\
\hline Year * $\mathrm{K} * \mathrm{Mg}$ & $920,506,956$ & 48 & $19,177,228.24$ & 0.421 & 1.000 \\
\hline Error & $1.368 \mathrm{E}+010$ & 300 & 45,595,972.16 & & \\
\hline Total & $1.061 \mathrm{E}+011$ & 399 & & & \\
\hline
\end{tabular}


The analysis of model D showed Table 6 that ANOVA and MIXED procedure were significant in the block-replication at $\mathrm{p}=0.05$ of the $\mathrm{F}$ test. In the block-year, only ANOVA of last 3 years was not significant.

The test did not show any significance in the levels of $\mathrm{K}$ and $\mathrm{Mg}$ and their interaction at $\mathrm{p}=0.05$ of the F-test.

\section{Conclusions}

This study has presented a general overview for four building models that accounted for possible sources of variance in the experimental trials of potassium and magnesium fertilizer applications on oil palm cultivation. Fixed Effect Analysis of Variances (ANOVA) method did not show significant differences in fertilizer treatments application. Hence there was a need to build some blocking models that were classified by their blocking and interacting mechanism as stated in the methodology to discern yield differences due to fertilizer treatments. Fixed effects represent the different levels of treatment structures for fertilizers application (potassium and magnesium). Random effects are included in the models as the replicates and years to be block. The Linear Mixed Model (LMM) was arrived at by dividing the mathematical equation into the fixed factors and random factors called mixed model equation, based on blocking mechanisms with different blocking interactions, crossing and nesting relationships between factors.

Thus,

$$
Y_{i j k l}=\mu \cdots+\alpha_{i}+\beta_{j}+r_{k}+t_{l}+(\alpha \beta)_{i j}+(\alpha t)_{i l}+(\beta t)_{j l}+(\alpha r)_{i k}+(\beta r)_{j k}+(\alpha \beta r)_{i j k}+(\alpha \beta t)_{i j l}+i j k
$$

revealed that the interaction between fertilizer potassium and magnesium showed that potassium at $3.5 \mathrm{~kg}$ and magnesium at $0 \mathrm{~kg}$ was sufficient enough for bunch yield of oil palm at the plantation for the first two years. Further evolved soil series specific fertilizer regimes for the oil palm on inland soils of Nigeria were achieved. It was also revealed that the blocking mechanism with regards to replicates and years was very significant in their various p-values for the different models.

This work has demonstrated the advantage of using mixed model analysis for potassium (K) and magnesium (Mg) fertilizer trials, thus identifying certain effects (no significant level for $\mathrm{K}$ and $\mathrm{Mg}$ ) that were hidden by Fixed Effect Analysis of Variance (ANOVA) was applied. The results also showed that potassium level was significant at $2.5 \mathrm{~kg}$ and above in the application of fertilizers. The test for blocks effect showed that there was significant effect in the blocks for the models developed. The analyses of mean yield against yearly application of potassium and magnesium showed that the highest yield was recorded in the first year (2000) with a total bunch weight of $24,000 \mathrm{~kg}$. The study concluded that contribution from potassium became significant as from potassium level $2.5 \mathrm{~kg}$ and above even when only the first two years were taken into consideration.

Table 6. Mixed model analysis for RCBD on influence of K and Mg for model D all 5 years.

\begin{tabular}{|c|c|c|c|c|c|}
\hline Source of Variation & SS & $\mathrm{DF}$ & MS & $\mathrm{F}^{*}$ & P-Value \\
\hline Blocks (Rep) & $3,615,760,339$ & 3 & $1,205,253,446$ & 76.348 & $0.033^{*}$ \\
\hline Block (Year) & 1,931,053,391 & 4 & $482,763,347.9$ & 41.874 & $0.005^{*}$ \\
\hline $\mathrm{K}$ & $57,837,735.8$ & 4 & $14,459,433.96$ & 0.915 & 0.577 \\
\hline $\mathrm{Mg}$ & $12,010,924.6$ & 3 & 4,003,641.539 & 0.117 & 0.950 \\
\hline $\mathrm{K} * \mathrm{Mg}$ & $298,259,830$ & 12 & 24,854,985.83 & 1.172 & 0.412 \\
\hline Rep * $\mathrm{K}$ & $408,428,414$ & 12 & $34,035,701.15$ & 0.941 & 0.519 \\
\hline $\operatorname{Rep} *$ Mg & $161,181,169$ & 9 & 17,909,018.83 & 0.495 & 0.868 \\
\hline Year * K & $254,341,158$ & 16 & $15,896,322.38$ & 0.829 & 0.948 \\
\hline Year * Mg & $177,717,796$ & 12 & $14,809,816.34$ & 0.772 & 0.675 \\
\hline $\mathrm{Rep} * \mathrm{~K} * \mathrm{Mg}$ & 1,301,704,178 & 36 & $36,158,449.39$ & 1.059 & 0.385 \\
\hline Year * $\mathrm{K} * \mathrm{Mg}$ & $920,506,956$ & 48 & $19,177,228.24$ & 0.562 & 0.991 \\
\hline Error & $8,191,717,546$ & 240 & $34,132,156.44$ & & \\
\hline Total & $1.061 \mathrm{E}+011$ & 399 & & & \\
\hline
\end{tabular}


The analysis of variance model for Randomized Complete Block Design (RCBD) was developed and used to demonstrate the analysis of data with fixed treatment and random block effects. Construction of analysis of variances table for RCBD with expected mean squares for all the models were well presented. Also, hypothesis relevant to each model was formulated and used to test for specific effects in the models, such as: fixed part, random part and interacting part using appropriate error terms as determined by their expected mean squares and restricted likelihood method (variances). The results were then obtained using data from oil palm fertilizer trials from NIFOR. The general data for the trials were classified into first two years, last three years and all five years.

However, mixed and ANOVA procedures may coincide with the use of more years in research.

\section{References}

[1] Airy, G.B. (1861) On the Algebraical and Numerical Theory of Errors of Observations and the Combinations of Observations. MacMillan, London.

[2] Bailey, R.A. (1981) A Unified Approach to Design of Experiments. Journal of the Royal Statistical Society, Series A, 144, 214-223. http://dx.doi.org/10.2307/2981920

[3] Saville, B.R. and Herring, A.H. (2009) Testing Random Effects in the Linear Mixed Model Using Approximate Bayes factors. Biometrika, 65, 369-376.

[4] Chi, E.M. and Reinsel, G.C. (1989) Models for Longitudinal Data with Random Effects and AR(1) Errors. Journal of the American Statistical Association, 84, 452-459. http://dx.doi.org/10.1080/01621459.1989.10478790

[5] Chiarandini, M. and Goegebeur, Y. (2010) Mixed Models for the Analysis of Optimization Algorithms. In: BartzBeielstein, T., Ed., Experimental Method for the Analysis of Optimization Algorithms, Springer, Berlin Heidelberg, 225-264. http://dx.doi.org/10.1007/978-3-642-02538-9 10

[6] Crump, S.L. (1947) The Estimation of Variance in Multiple Classification. PhD Thesis, Department of Statistics, Iowa State University, Ames.

[7] Dempster, A.P., Laird, N.M. and Rubin, D.B. (1977) Maximum Likelihood from Incomplete Data via the EM Algorithm. Journal of the Royal Statistical Society, Series B, 39, 138.

[8] Thisted, R.A. (1988) Elements of Statistical Computing. Chapman Hall, London.

[9] Lindstrom, M.J. and Bates, D.M. (1988) Newton-Raphson and EM Algorithms for Linear Mixed-Effects Models for Repeated-Measures Data. Journal of the American Statistical Association, 83, 1014-1022.

[10] Duchateau, L., Janssen, P. and Rowlands, J. (1998) Linear Mixed Models, an Introduction with Applications in Veterinary Research. International Livestock Research Institute, Kenya.

[11] Fisher, R.A. (1925) Statistical Methods for Research Workers. Oliver and Boyd, London.

[12] Fisher, R.A. (1935) Contribution to the Discussion of “Complex Experiments” by F. Yates. J. R. Statist. Soc, 2, 23-31

[13] Foster, H.L. and Tarmizi, M.A. (1988) Variation in the Fertilizer Requirements of Oil Palm in Peninsular Malaysia. I. Within the Same Series. PORIM Bulletin, 16, 1-9.

[14] Foster, H. (2003) Assessment of Oil Palm Fertilizer Requirements. In: Fairhurst, T.H. and Hardter, R., Eds, Oil Palm: Management for Large and Sustainable Yields, Potash and Phosphate Institute (PPI), Potash and Phosphate Institute of Canada (PPIC) and International Potash Institute, 231-257

[15] Gelfand, A.E., Hills, S.E., Racine-Poon, A. and Smith, A.F.M. (1990) Illustration of Bayesian Inference in Normal Data Models Using Gibbs Sampling. Journal of the American Statistical Association, 85, 972-985. http://dx.doi.org/10.1080/01621459.1990.10474968

[16] Gelman, A. (2006) Analysis of Variance. Columbia University, New York. http://dx.doi.org/10.1017/cbo9780511790942.028

[17] Hartley, H.O. and Rao, J.N.K. (1967) Maximum-Likelihood Estimation for the Mixed Analysis of Variance Model. Biometrika, 54, 93-108. http://dx.doi.org/10.1093/biomet/54.1-2.93

[18] Harville, D.A. (1977) Maximum Likelihood Approaches to Variance Components Estimation and to Related Problems. Journal of the American Statistical Association, 72, 320-338. http://dx.doi.org/10.1080/01621459.1977.10480998

[19] Harville, D.A. and Mee, R.W. (1984) A Mixed-Model Procedure for Analyzing Ordered Categorical Data. Biometrics, 40, 393-408. http://dx.doi.org/10.2307/2531393

[20] Henderson, C.R. (1953) Estimation of Variance and Covariance Components. Biometrics, 9, 226-252. http://dx.doi.org/10.2307/3001853

[21] Henderson, C.R., Kempthorne, O., Searle, S.R. and von Krosigk, C.M. (1959) The Estimation of Environmental and 
Genetic Trends from Records Subject to Culling. Biometrics, 15, 192-218. http://dx.doi.org/10.2307/2527669

[22] Henderson, C.R. and Quaas, R.L. (1976) Multiple Trait Evaluation Using Relative’s Records. Journal of Animal Science, 43, 11-88.

[23] Henderson, C.R. (1990) Statistical Method in Animal Improvement: Historical Overview. In: Gianola, D. and Hammond, K., Eds., Advances in Statistical Methods for Genetic Improvement of Livestock, Springer-Verlag, Berlin, 2-14. http://dx.doi.org/10.1007/978-3-642-74487-7_1

[24] Jennrich, R.I. and Schluchter, M.D. (1986) Unbalanced Repeated Measures Models with Structural Covariance Matrices. Biometrics, 42, 805-820. http://dx.doi.org/10.2307/2530695

[25] Laird, N.M. and Ware, J.H. (1982) Random-Effects Models for Longitudinal Data. Biometrics, 38, $963-974$. http://dx.doi.org/10.2307/2529876

[26] Liang, K.-Y. and Zeger, S.L. (1986) Longitudinal Data Analysis Using Generalized Linear Models. Biometrika, 73, 1322. http://dx.doi.org/10.1093/biomet/73.1.13

[27] Makinde, E.A., Oluwa, O.K., Oke, A.O. and Duyile, P.O. (2010) Effects of Organic, Organomineral and NPK Fertilizer Treatments on Fresh and Dry Matter Yield of Amaranthus cruentus L. on Soil Types in Lagos, Nigeria. New York Science Journal, 3, 12-17.

[28] Melaniel, L.B. and Grunwald, G.K. (2004) Mixed Model for the Analysis of Replicated Spatial Point Patterns. Biostatistics, 5, 633-648.

[29] Miller, J.J. (1977) Asymptotic Properties of Maximum Likelihood Estimates in the Mixed Model of the Analysis of Variance. The Annalds of Statistics, 5, 746-762. http://dx.doi.org/10.1214/aos/1176343897

[30] Patterson, H.D. and Thompson, R. (1971) Recovery of Inter-Block Information when Block Sizes Are Unequal. Biometrika, 78, 609-619.

[31] Piepho, H.P., Buchse, A. and Emrich, K. (2003) A Hitchhiker's Guide to Mixed Models for Randomized Experiments. Journal of Agronomy and Crop Science, 189, 310-322. http://dx.doi.org/10.1046/j.1439-037X.2003.00049.X

[32] Piepho, H.P., Buchse, A. and Richter, C. (2004) A Mixed Modelling Approach for Randomized Experiments with Repeated Measures. Journal of Agronomy and Crop Science, 190, 230-247. http://dx.doi.org/10.1111/j.1439-037X.2004.00097.x

[33] Smith, A.B., Cullis, B.R. and Thompson, R. (2005) The Analysis of Crop Cultivar Breeding and and Evaluation Trials: An Overview of Current Mixed Model Approaches. Journal of Agricultural Science, 143, 449-462. http://dx.doi.org/10.1017/S0021859605005587

[34] Wakefield, J.C., Smith, A.F.M., Racine-Poon, A. and Gelfand, A.E. (1994) Bayesian Analysis of Linear and Nonlinear Population Models Using the Gibbs Sampler, Applied Statistics. 143-152.

[35] Witkovský, V. (2001) MATLAB Algorithm Mixed.M for Solving Henderson’s Mixed Model Equations. Technical Report, Institute of Measurement Science, Slovak Academy of Sciences, Bratislava.

[36] Yeboah, S., Akromah, R. and Quansah, C. (2012) Organic and Inorganic Fertilizers Application on the Growth and Yield of Artemisia annua L. in the Humid Tropics of Ghana. African Journal of Agricultural Research, 7, 177-182. http://dx.doi.org/10.5897/AJAR11.679

[37] Jun, Z. (1993) Mixed Model Approaches for Estimating Genetic Covariances between Two Traits with Unequal Design Matrices. Journal of Biomathematics, 8, 24-30. 


\section{Submit or recommend next manuscript to SCIRP and we will provide best service for you:}

Accepting pre-submission inquiries through Email, Facebook, LinkedIn, Twitter, etc.

A wide selection of journals (inclusive of 9 subjects, more than 200 journals)

Providing 24-hour high-quality service

User-friendly online submission system

Fair and swift peer-review system

Efficient typesetting and proofreading procedure

Display of the result of downloads and visits, as well as the number of cited articles

Maximum dissemination of your research work

Submit your manuscript at: http://papersubmission.scirp.org/ 